Available online at GSC Online Press Directory

GSC Biological and Pharmaceutical Sciences

e-ISSN: 2581-3250, CODEN (USA): GBPSC2

Journal homepage: https://www.gsconlinepress.com/journals/gscbps

(RESEARCH ARTICLE)

\title{
Assessment of drug utilization patterns in paediatric patients in comparison with
} WHO core indicators

\author{
Biradar S. M 1, ${ }^{*}$, Khaja Hussain B. S ${ }^{1}$, G. Urmila ${ }^{1}$, K. Vaishnavi ${ }^{1}$, Biradar Siddanagouda ${ }^{2}$, Sorangavi Vijaya ${ }^{2}$, \\ Marapur S. C ${ }^{1}$ and Kalyane N. V 1
}

${ }^{1}$ Department of Pharm. D Programme, SSM College of Pharmacy and Research Centre, Vijaypur-586103.

${ }_{2}^{2}$ Department of Medicine, Shri B M. Patil Medical College Hospital and Research Centre, Vijaypur-586103.

Publication history: Received on 20 October 2019; revised on 13 November 2019; accepted on 14 November 2019

Article DOI: https://doi.org/10.30574/gscbps.2019.9.2.0199

\begin{abstract}
Drugs utilization should be rational in specialized population, especially in pediatrics because, the physiology of pediatrics patients differs from adult population such that the special care is required while prescribing drugs to the pediatric patients. Hence the current study was under taken to study the prescribing pattern of drugs in pediatric patients using WHO core indicators, which includes Prescription audit, length of hospitalization, cost of drugs per prescription and pharmaceutical care in pediatric population. A prospective and observational study was conducted in a pediatric department of teritiary care hospital over a period of 6 months. A study sample size was 161 patients, who met the criteria and data were extracted appropriately and analyzed. Out of 161 patients, males were 85 and females were 76 and majority was found between in the age group of 0-4 years. Majority of prescriptions containing 5-6 drugs per prescription. Parenteral route of drug administration were the most common route of drug administration. The commonly prescribed classes of drugs were Anti-Infective agents. The average cost of per prescription was INR. 1179.7 during hospital stay. The length of hospitalization was 4-5 days in 47.2\% of admitted patients. Pharmaceutical care interventions were performed on necessary basis and it was accepted and made necessary changes. In the present study most of prescribing pattern was comparable to WHO core indicators which influences the rationality of prescribing pattern in pediatric population which improves the patient's quality of life, reduces length of hospital stay and socioeconomic burden.
\end{abstract}

Keywords: Prescribing pattern; Prescription audit; Length of hospital stay; Pharmaceutical care; Pediatric patients

\section{Introduction}

Studies on the process of drug utilization focus on factors Drug utilization Pediatrics is the branch of science that deals with the medical care of infants, children and adolescents. Prescribing and drug utilization patterns mainly focus on factors related to prescribing, dispensing, administering and taking of medication and its associated events. Paediatrics physiology is different when compared to that of adults so drug utilization patterns study plays a vital role in helping the health-care system to understand, interpret and improve the prescribing, administration, to curtail adverse events and rational use of medications [1]. Many studies have been conducted to evaluate the drug prescribing patterns in adults and have established literature but such studies in children are limited due to ethical concerns such that less literature is available. So that children have to be monitored on daily basis as they are more prone to adverse events related to the medications [2].

Paediatric populations are more prone to suffer from recurrent infections of the respiratory tract and gastrointestinal system. Lower respiratory tract infections are the leading cause of death in children below 5 five years of age. Majority

\footnotetext{
${ }^{*}$ Corresponding author

E-mail address: smbiradar@rediffmail.com
}

Copyright (C) 2019 Author(s) retain the copyright of this article. This article is published under the terms of the Creative Commons Attribution Liscense 4.0 
proportion of the paediatrics hospital visits are due to the common childhood illnesses such as acute respiratory infection, acute watery diarrhea and viral fever [3].

There are many drugs available for the similar medical condition, prescribing practices are the reflection of health professional's abilities to determinate among the various choices of drugs and determine the ones that will most benefit the patients by analyzing the benefit risk ratio. Children comprise about $40 \%$ of India's population. Drug therapy is considered to be main element of paediatrics health care management. Successful medical treatment of paediatric patient is based upon a correct diagnosis and best possible course of drug therapy, which usually involves a medication regimen with minimum rate of adverse events occurrence [4].

Prescriptions are mainly classified as rational and irrational considering factors such as efficacy, safety and the cost effectiveness. The irrational prescriptions may have possible consequences such as adverse drug reactions, increased frequency of drug-drug, drug-food and drug-disease interactions and increased healthcare costs. Adverse drug reactions in children particularly could contribute to morbidity and mortality because of the immaturity of their immune system, physiology and their inability to communicate adequately affecting their quality of life [5].

The unnecessary and irrational usage of drugs such as polypharmacy, use of inappropriate drugs not related to the diagnosis, off- label usage, formulation which is non-compliance, overuse and misuse of drugs (antibiotic, antidepressants and vitamins \& mineral supplements) and unnecessary use of injectable drugs. These together may incur extra cost burden leading to the non adherence to the medication, adverse effects, increased drug related problems, resistance to the drugs particularly antibiotic resistance which may have much serious effects over further drug usage, increased hospitalization and increased morbidity \& mortality. This study is therefore aimed at investigating the prescribing, dispensing and administrating practices at a representative sample of health care facilities using WHO drug use indicators [6].

The pharmaceutical care is essential in paediatric population due to their altered physiology; pharmacokinetics and pharmacodynamics from adult populations which make paediatric population easily prone to drug related problems, medication errors, therapeutic duplication and medication errors. Pharmaceutical companies marketing drugs for children's medicines tend to be small and the range of doses used may be wide for any drug formulation because many drugs prescribed widely for infants and children are not available in suitable dosage forms and compatible formulations leading to a lack of attention and updated knowledge towards paediatric medicines. Knowledge of drug administration in children and infants lags behind that of adults for many reasons including developmental differences that affect the pharmacodynamics and pharmacokinetic profiles of drugs as these studies are mainly carried out in adults whose physiology differ from that of children's, ethical and financial reasons, research capabilities, and regulatory guidelines, constraint and consent to participate in the research studies. A study conducted on paediatric drug prescribing in Trinidad revealed that $44 \%$ of the total patients had received one or more antibiotics among which $70.8 \%$ antibiotics are prescribed for paediatric patients $[7,8]$.

Children's take different medications for different medical conditions frequently and mean number of drugs per prescription is high so interventions have an unrelenting effect over a very long period of time [9].

Children's are often frequently exposed group of population to adverse effects of the drugs as their physiological, pharmacokinetic and pharmacodynamics is different from that of the adults. The adverse effect of the drugs in children doesn't contain much literature evidence from the studies as such studies are limited in children's. Prescribing and administrating of drugs to children needs expertise and updated knowledge as doses and formulations prescribed for children's are not commercially available in the market and sometimes they may also be prescribed for off- label use. Rational use of drugs is important for every patient, especially extremely important in case of children's [10]. Hence the present study was conducted in order to study the prescribing pattern of drugs in paediatric population in comparison with WHO core indicators which includes, number of drugs prescribed, class of drugs of drugs prescribed, cost effective study, length of hospitability and necessary clinical pharmacist intervention if, necessary.

\section{Material and methods}

A hospital based prospective observational study conducted for a period of six months in the paediatric department of Shri B. M. Patil medical college hospital and research centre, Vijayapura, Karnataka. The patients admitted to paediatric ward were screened according to inclusion and exclusion criteria and sample size of 161 patients were calculated with the help of biostatistician for the present study. 


\subsection{Inclusion criteria}

- $\quad$ Provisionally diagnosed inpatients are included.

- Both the genders in pediatrics ward are included.

- Patients or their relative member who were willing to provide consent form.

\subsection{Exclusion criteria}

- Out Patients of all departments are excluded.

- Patients with incomplete records or case files were excluded.

- $\quad$ AMA (Against Medical Advice) cases are excluded.

\subsection{Source of data}

The data used for the study was obtained from Patient case files (consists of demographic details, past medical history, past medication history, clinical characteristics, social history, blood pressure readings, brand name of drugs, drug, dosages, type of formulation and duration of the patient's treatment), Micromedex online drug data base, Shockley's Drug-Drug interaction book and Standard Text, Journals, Research articles and Newsletters.

\subsection{Data collection and assessment}

The case files of the inpatients are reviewed to evaluate drug utilization patterns and to see if WHO core indicators usage has been implemented in the prescribing patterns such as evaluated dose, dosage form, frequency, route of administration, interactions with other drugs, and adverse drug reactions. Auditing of drug chart (Prescription Auditing) evaluated the factors that were related to the prescribing patterns by physicians and cost effectiveness.

\subsection{Statistical analysis}

The number of patients and percentage of data were calculated with the help of regular Microsoft excel 2007 sheet and the sample size was calculated by the help Biostatistician using the below equation.

$$
\mathrm{n}=\mathrm{Z}^{2} \times \mathrm{P}(1-\mathrm{P}) / \mathrm{d}^{2}
$$

$\mathrm{Z}=5 \%$ level of significance,

$\mathrm{P}=$ Proportion value of important parameter,

$\mathrm{d}=$ Margin of error.

A sample size of 161 subjects will allow the study to determine the pattern of analgesics given to the patient with $95 \%$ confidence level and margin of error of $+/-5 \%$ with finite population correction.

\section{Results}

Out of 161pediatric population maximum number of patients was found between 0-4 years and minimum number of patients of age group5-9 years (Table 01). Among selected patients males were (85) more in number when compared to females (76) (Table 02). In all age groups female population were more in number when compared to the male population except in the age groups of 0-4, where male populations were more than females (Table 03).

Table 1 Distribution of patients according to age

\begin{tabular}{|c|c|c|c|c|c|}
\hline Age (yrs) & & & $\mathbf{N}$ & & $\%$ \\
\hline $0-4$ & & & 68 & & 42.2 \\
\hline $5-9$ & & & 46 & & 28.6 \\
\hline $\begin{array}{l}10-14 \\
\text { Total }\end{array}$ & & & $\begin{array}{l}47 \\
161 \\
\end{array}$ & & $\begin{array}{l}29.2 \\
100 \\
\end{array}$ \\
\hline & Min & Max & & Mean & SD \\
\hline Age & 0.1 & 14 & & 6.4 & 4.6 \\
\hline
\end{tabular}


Table 2 Gender distribution

\begin{tabular}{lll}
\hline Gender & $\mathbf{N}$ & $\mathbf{\%}$ \\
\hline Male & 85 & 52.8 \\
Female & 76 & 47.2 \\
Total & 161 & 100 \\
\hline
\end{tabular}

Table 3 Age and gender distribution

\begin{tabular}{llllll}
\hline \multirow{2}{*}{ Age (yrs) } & Male & \multicolumn{3}{c}{ Female } & p value \\
\cline { 2 - 5 } & $\mathbf{N}$ & $\mathbf{\%}$ & $\mathbf{N}$ & $\mathbf{\%}$ & \\
\hline $0-4$ & 44 & 51.8 & 24 & 31.6 \\
$5-9$ & 19 & 22.4 & 27 & 35.5 & 0.03 \\
$10-14$ & 22 & 25.9 & 25 & 32.9 & \\
\hline Total & 85 & 100.0 & 76 & 100.0 \\
\hline
\end{tabular}

Table 4 Distribution of patients according to duration of hospitalization

\begin{tabular}{|c|c|c|c|}
\hline Duration of Hospitalization (Days) & No of patients & $\%$ & \\
\hline $2-3$ & 27 & 16.8 & \\
\hline $4-5$ & 76 & 47.2 & \\
\hline $6-7$ & 30 & 18.6 & \\
\hline$>7$ & 28 & 17.4 & \\
\hline \multirow[t]{2}{*}{ Total } & 161 & 100 & \\
\hline & Max. & Mean & SD \\
\hline Duration of Hospitalization & 15 & 5.5 & 2.5 \\
\hline
\end{tabular}

Majority of the Patients were hospitalized for 4-5 days followed by 6-7 days, $>7$ days and 2-3 days (Table 04). In total 161 cases, cases containing frequency of 5-6 drugs per prescription were more commonly prescribed than the cases containing 7-8, 9-10, 3-4 and >10 drugs which were prescribed less commonly (Table 05).

Table 5 Distribution of cases according to number of drugs per prescription

\begin{tabular}{lllll}
\hline No of Drugs per Prescription & N & \% & \\
\hline $3-4$ & & 20 & 12.4 & \\
$5-6$ & 53 & 32.9 & \\
$7-8$ & & 50 & 31.1 & \\
$9-10$ & & 28 & 17.4 & \\
$>10$ & & 10 & 6.2 & \\
\hline Total & & 161 & Mean & SD \\
\hline No of Drugs & per & Min & Max & 2.2 \\
\cline { 2 - 6 } Prescription. & 3 & 15 & 6.9 & 200 \\
\hline
\end{tabular}


Table 6 Distribution of cases according to dosage forms

\begin{tabular}{lll}
\hline Route of administration & $\mathbf{N}$ & $\mathbf{\%}$ \\
\hline Injection & 140 & 87.0 \\
IVF & 128 & 79.5 \\
Syrup & 108 & 67.1 \\
Tablets & 51 & 31.7 \\
Powders & 47 & 29.2 \\
Nebulization & 30 & 18.6 \\
Drops & 14 & 8.70 \\
Ointments & 09 & 5.60 \\
Capsules & 07 & 4.30 \\
\hline
\end{tabular}

When compared to all the dosage forms, drugs given through I.V route were more frequent followed by intravenous route drugs given through oral route were more. In the oral route of administration syrups were more frequently prescribed as children's were more compatible to take syrups due their flavoring taste and easier administration than the tablets followed by powders, drops and capsules (Table 06).The current study reveals patients charged 500-1000 rupees were more compared to $<500,1000-1500,1500-2000$ and $>2000$ rupees (Table 07).

Table 7 Distribution of cases according to cost of drugs per prescription

\begin{tabular}{lllll}
\hline Cost of Drugs & N & & \% & \\
\hline$<500$ & 24 & & 14.9 & \\
$501-1000$ & 62 & & 38.5 & \\
$1001-1500$ & 38 & & 23.6 & \\
$1501-2000$ & 15 & & 9.30 & \\
$>2000$ & 22 & & 13.7 & \\
\hline Total & 161 & & 100 & \\
\hline & Min. & Max. & Mean & SD \\
Cost of Drugs per prescription & 116.41 & 4159.79 & 1179.7 & 788.3 \\
\hline
\end{tabular}

The prescriptions were classified and evaluated according to the pharmacological action of drugs and the most of the prescriptions Anti-Infectives (146), Non- Steroidal Anti- inflammatory Drugs (99), Proton- pump inhibitor (74), Bronchodilators (70),Vitamins and Mineral Supplements (65), Anti-emetics (35), Anti-spasmodic (16), Anti-epileptic (12), Nasal Decongestants (7), Glucocorticosteroids (7), Laxatives and Purgatives (7) and Others (83) (Table 08).

Table 8 Distribution of cases according to therapeutic drugs class

\begin{tabular}{lll}
\hline Therapeutic classes & $\mathbf{N}$ & $\mathbf{\%}$ \\
\hline Anti-Infective & 146 & 90.7 \\
Non- Steroidal Anti- inflammatory Drugs & 99 & 61.5 \\
Proton- pump inhibitors & 74 & 46.0 \\
Bronchodilators & 70 & 42.0 \\
Vitamins and Mineral Supplements & 65 & 40.4 \\
Anti-emetics & 35 & 21.7 \\
Anti-spasmodics & 16 & 09.9 \\
Anti-epileptic & 12 & 7.5 \\
Nasal Decongestants & 7 & 4.3 \\
Glucocorticosteroids & 7 & 4.3 \\
Laxatives and Purgatives & 1 & 0.60 \\
Others & 83 & 51.6 \\
\hline
\end{tabular}


The commonly prescribed classes of drugs were Anti-Infectives accompanied by Non steroidal anti inflammatory drugs proton pump inhibitors, iron and Vitamins and Mineral Supplements and anti infective agents. In majority of the cases class of anti infective drugs are prescribed than other classes of drugs (Table 09).

Table 9 Distribution of cases according to common drugs prescribed

\begin{tabular}{lll}
\hline Common drugs prescribed & No. of cases & $\mathbf{\%}$ \\
\hline Non-Steroidal Anti-inflammatory drugs & 92 & 57.1 \\
Proton Pump Inhibitors & 76 & 47.2 \\
Vitamins and Mineral Supplements & 40 & 24.8 \\
Anti-infectives & 148 & 91.9 \\
\hline
\end{tabular}

In the Prescription audit 15 parameters were taken into consideration, out of which only one prescription met the all the parameters of prescription audit. 13-14 parameters were comparable by 13 cases; $10-12$ parameters were comparable by 135 cases (Table 10 ).

Table 10 Prescription audit in comparison with WHO core indicators

\begin{tabular}{lll}
\hline Prescription parameters & N & \% \\
\hline$<10$ & 012 & 07.5 \\
$10-12$ & 135 & 83.9 \\
$13-14$ & 013 & 08.1 \\
$\geq 15$ & 001 & 00.6 \\
\hline Total & 161 & 100 \\
\hline
\end{tabular}

The percentage of drugs prescribed by generic name and percentage of drugs from essential drug list were compliant with WHO standards, average number of drugs per encounter and percentage of encounters with antibiotics and percentage of encounters with injections were non compliant with the WHO standards or criteria (Table 11). Pharmaceutical care plan was provided in terms of drug-drug interaction check and intervened in major issues and it was accepted and taken necessary actions (Table 12).

Table 11 Prescribing indicators in comparison with WHO

\begin{tabular}{lll}
\hline Prescribing indicators Assessed & $\begin{array}{l}\text { Results } \\
\text { percentage) }\end{array}$ & $\begin{array}{l}\text { (Average Standard or } \\
\text { criteria (\%) }\end{array}$ \\
\hline Average number of drugs per encounter & 6.9 & $1.6-1.8 \%$ \\
Percentage of drugs prescribed by generic name & 25.11 & $100 \%$ \\
Percentage of encounters with antibiotics & 38.9 & $20-26.8 \%$ \\
Percentage of encounters with injections & 56.2 & $13.4-24.1 \%$ \\
Percentage of drugs from essential drug list & 90.2 & $100 \%$ \\
\hline
\end{tabular}


Table 12 Pharmaceutical care plan

\begin{tabular}{|c|c|c|c|c|c|c|}
\hline \multirow{2}{*}{$\begin{array}{l}\text { Sr. } \\
\text { No. }\end{array}$} & \multicolumn{3}{|c|}{ Drug- Drug interaction } & \multirow{2}{*}{$\begin{array}{l}\text { Severity } \\
\text { Major }\end{array}$} & \multirow{2}{*}{$\begin{array}{l}\text { Effect } \\
\text { Concurrent use of } \\
\text { Ceftriaxone and Calcium } \\
\text { gluconate may result in } \\
\text { formation of Ceftriaxone- } \\
\text { calcium precipitates is } \\
\text { contraindicated in neonates. }\end{array}$} & \multirow[b]{2}{*}{$\begin{array}{l}\text { Intervention } \\
\text { Fatal reaction with } \\
\text { Ceftriaxone+Calcium } \\
\text { precipitate in the } \\
\text { lungs and kidneys of } \\
\text { new born. Do not } \\
\text { mix or administer } \\
\text { concurrently with } \\
\text { calcium gluconate in } \\
\text { the same IV } \\
\text { administration line. } \\
\text { Advice was accepted. }\end{array}$} \\
\hline & $\begin{array}{l}\text { Ceftriaxone } \\
\text { gluconate }\end{array}$ & + & Calcium & & & \\
\hline 2. & \multicolumn{3}{|c|}{ Ondansetron + Linezolid } & Major & $\begin{array}{l}\text { Using Ondansetron together } \\
\text { with Linezolid can increase } \\
\text { the risk of rare but serious } \\
\text { conditions called Serotonin } \\
\text { Syndrome which may } \\
\text { include symptoms such as } \\
\text { confusion, hallucinations, } \\
\text { seizures, extreme change in } \\
\text { blood pressure. }\end{array}$ & $\begin{array}{l}\text { Immediate medical } \\
\text { attention is needed } \\
\text { in severe cases and } \\
\text { avoid the usuage of } \\
\text { Ondansetron and } \\
\text { Linezolid } \\
\text { concurrently. } \\
\text { Advice was accepted. }\end{array}$ \\
\hline 4. & \multicolumn{3}{|c|}{ Azithromycin+Ondansetron } & Moderate & $\begin{array}{l}\text { Resulted in the risk of QT } \\
\text { interval prolongation. }\end{array}$ & $\begin{array}{l}\text { If concurrent } \\
\text { therapy is required, } \\
\text { ECG monitoring is } \\
\text { recommended. } \\
\text { Advice was accepted. }\end{array}$ \\
\hline
\end{tabular}

\section{Discussion}

A prospective observational study was conducted to assess drug utilization pattern and cost effective treatment in paediatrics patients. The focus of this study was to review the prescriptions for rational drug prescribing. The ultimate aim of the study was to that it can be beneficial to society by improving prescribing patterns.

Total number of 161 patients was included in the study. In the study the patients of age group from 0-4 years (68) are more followed by 10-14 years (47) and 5-9 years (46) which was partially similar to the study conducted by Achalu T where highest number of patients were of age group 0-4 years followed by 5-9 years and 10-14 years.In the study, out of 161 patients; males were 85, dominant than females 76 which was contradicted to study conducted by Harshal $\mathrm{N}$ Pise where highest numbers of patients studied were females.

In all age groups female population were more in number when compared to the male population except in the age groups of $0-4(51.8 \%)$, where male populations were more than females. In the study patients were categorized according to the number of days hospitalized and more number of patients were hospitalized for 4-5 days (76) followed by 6-7 days (30),>7 days (28) and 2-3 days (27) which was contradicted to the study conducted by Achalu T where patients were categorized in to 1-4 days, 5-9 days, 10-14 days, 15-19 days and $>20$ days of hospitalization. In 161 cases observed the prescriptions containing 5-6 drugs (53) were more followed by 7-8 drugs (50), 9-10 drugs (28), 3-4 drugs(20) and > 10 drugs(10) per prescription.

Various drug formulations were prescribed in the study, highest being Injections (87\%), followed by IVF (79.5\%), syrups (67.1\%), tablets (31.7\%), Powders (29.2\%), Nebulization (18.6\%), Drops (8.7\%) ointments (5.6\%), and Capsules (4.3\%). The injectable doses forms of drugs are generally more costly than oral and other routes of administration. If used irrationally, it may unnecessarily increase the days of hospitalization and cost of the treatment. 
The injections and IVF utilization in this study is high which was $87 \%$ and $79.5 \%$ respectively in 161 cases, which was not in accordance with the study carried by Rehan and Lal.

In the study cost of the prescription drugs were calculated where 62 prescriptions cost ranged between $501-1000$ rupees (Rs), 38 prescriptions between 1001-1500 rupees (Rs), 24 prescriptions with < 500 rupees (Rs), 22 prescriptions with >2000 rupees (Rs) and 15 prescriptions between 1501-2000 rupees (Rs). The prescription with high cost was Rs 4159.79 /- and the prescription with the low cost was Rs 116.41.

The prescriptions were classified and evaluated according to the pharmacological action of drugs and the most of the prescriptions Anti-Infectives (146), Non- Steroidal Anti- inflammatory Drugs (99), Proton- pump inhibitor (74), Bronchodilators (70),Vitamins and Mineral Supplements (65), Anti-emetics (35), Anti-spasmodic (16), Anti-epileptic (12), Nasal Decongestants (7), Glucocorticosteroids (7), Laxatives and Purgatives (7) and Others (83) which was similar to the study conducted by Venkateswaramurthy $\mathrm{N}$. The prescriptions were also analyzed for most commonly prescribed classes of drugs and the majority of the prescriptions contain Anti-infectives (91.9\%) accompanied by Non Steroidal Anti- Inflammatory drugs(57.1\%), Proton Pump Inhibitors(47.2\%) and vitamins and mineral supplements(24.8\%).

In the study Prescription audit of 161 cases was assessed based on 15 parameters and most of the cases comply with 10-12 parameters (135) followed by 13-14 parameters (13), <10 parameters (12) and 15 parameters (1). The percentage of drugs prescribed by generic name (25.11\%) and percentage of drugs from essential drug list (90.2\%) were compliant with WHO standards, average number of drugs per encounter $(6.9 \%)$ and percentage of encounters with antibiotics (38.9\%) and percentage of encounters with injections (56.2\%) were non-compliant with the WHO standards or criteria.

\section{Conclusion}

The study provides the baseline data regarding prescribing practices in paediatrics inpatient department. The results also shows that the most commonly prescribed route of administration was Injections and IVF which impose higher cost than any other routes. It also highlights the problem of overprescribing of Anti-Infectives in overtime which may results into antibiotic resistance. Prescription auditing shows that average number of drugs per encounter; Percentage of encounters with antibiotics and Percentage of encounters with injections were non comparable with the WHO recommended standards and need to improvise while Percentage of drugs prescribed by generic name and Percentage of drugs from essential drug list were comparable with the WHO recommended standards. The results show that there is a need to improve prescription pattern by generic name and drugs from Essential Drug List. Despite of limited sample size, our study could contribute towards improvement in prescription pattern and implement institutional guidelines. In addition, there is scope for collaborative practice among doctors, clinical pharmacist and other health care practitioners for rational selection of pharmacotherapy in comparable to WHO care indicators in different clinical settings.

\section{Compliance with ethical standards}

\section{Acknowledgments}

Authors are thankful to Principal and Management Shri B M. Patil medical college hospital and SSM college of Pharmacy and research centre for providing the necessary facility to conduct the current research work.

\section{Disclosure of conflict of interest}

The authors declare that they have no conflict of interest.

\section{References}

[1] Thiruthopu SN et.al. (2014). Drug utilization pattern in south Indian pediatric population. Perspectives in Clinical Research, 5(4), 178-183.

[2] Pise NH et.al. (2015). Drug prescribing and dispensing pattern in pediatrics outpatient clinic of a rural tertiarycare teaching hospital. National Journal of Physiology, Pharmacy and Pharmacology, 5(4), 313-317.

[3] Venkateswaramurthy N, Faisal M and kumar RS. (2017). Assessment of drug usage patterns in pediatric patients. Pharm. Sci. \& Res, 9(2), 81-84. 
[4] Thapaliya k et.al. (2015). Prescribing patterns of antibiotics in paediatric hospital in chitwan district in Nepal. World Journal of Pharmacy and Pharmaceutical Sciences, 4(1), 1631-1641.

[5] Joseph F, Oladele O, Oludare 0 and Olatunde 0. (2015). Drug prescribing pattern for under-fives in a pediatric clinic in south-western nigeria. Ethiop J Health Sci, 25(1), 73-78.

[6] Chedi BAZ, Aguye IA and Kwanashie HO. (2015). Drug use pattern in out-patient children: A comparison between primary and secondary health care facilities in Northern Nigeria. African Journal of Pharmacy and Pharmacology, 9(4), 74-80.

[7] Achalu. T and Mensa. M. (2017). Drug Use pattern of Antibiotics in Paediatric Ward of Shenan Gibe Hospital, Oromia Region, Ethiopi Journal of Antibiotics Research, 1(1), 1-10.

[8] Gortmaker LS et.al. (2015). Cost Effectiveness of Childhood Obesity Interventions. American Journal of Preventive Medicine, 49(1), 102-111.

[9] Balushi AK, Sawafi F, Ghafri F and Zakwani.l I. (2013). Drug utilization pattern in an omani pediatric population. J basic clin pharm, 4(3), 68-72.

[10] Bergicho M, Mohammed AM and Wabe TN. (2012). Assessment of the pattern of drug prescribing in paediatrics ward in tertiary setting hospital in Addis Ababa, Ethiopia. Gaziantep Med J, 18(2), 61-65.

\section{How to cite this article}

Biradar SM, Khaja Hussain BS, G. Urmila, K. Vaishnavi, Biradar S, Sorangavi V, Marapur SC and Kalyane NV. (2019). Assessment of drug utilization patterns in paediatric patients in comparison with WHO core indicators. GSC Biological and Pharmaceutical Sciences, 9(2), 84-92. 